\title{
Komplikasi Bedah, Luaran Fungsi Menstruasi dan Seksual dari Prosedur Vaginoplasti Sigmoid pada Pasien dengan Agenesis Vagina
}

\author{
Roy Jansen Sinaga ${ }^{1}$, Nuring Pangastuti ${ }^{2}$, Ova Emilia ${ }^{3}$ \\ ${ }^{1,2,3}$ Departemen Obstetri Ginekologi \\ Fakultas Kedokteran, Kesehatan Masyarakat dan Keperawatan Universitas Gadjah Mada \\ Korespondensi: ${ }^{1}$ roy.jansa@gmail.com/081393862084, 2nuring_nw@yahoo.co.id/08122703752
}

Submisi: 4 desember 2019; Revisi: 20 Okotber 2020; Penerimaan: 27 Oktober 2020

\begin{abstract}
Background: Vaginal agenesis is one form of abnormality found in the uroginecology with a prevalence of 1: 4000 births. Various reconstruction techniques, both non-surgical and surgical, have been introduced, one of which is sigmoid vaginoplasty. Research on the complications and outcomes of sigmoid vaginoplasty procedure is still limited.

Objective: To assess surgical complications, sexual and menstrual function outcomes of sigmoid vaginoplasty procedure.

Method: This is a prospective study. A total 11 patients with a variety of genital tract malformations have been performed for sigmoid vaginoplasty during January 2017 to January 2019. Data are described descriptively-analytically. All patients were assessed for surgical complications, menstrual and sexual function after surgery.

Result and Discussion: A total of 10 cases (90.9\%) were diagnosed with vaginal agenesis and 1 case $(9.1 \%)$ was diagnosed with Mayer-RokitanskyKüster-Hauser (MRKH) syndrome. Durante surgery complications are severe bleeding and rectum injury, occurred in 2 cases (18.2\%). Postoperative complication is surgical wound dehiscence, occurred in 2 cases (18.2\%). All patients who have uterus (100\%) showed good menstrual function outcomes. Of the 3 married patients, all patients (100\%) showed good postoperative sexual function outcomes (FSFI score 27-30.4).

Conclusion: The sigmoid vaginoplasty procedure is an effective procedure for patients with agenesis vaginal. This procedure has low surgical complications with good outcomes of menstrual and sexual function.
\end{abstract}

Keywords: Sigmoid vaginoplasty; vaginal agenesis; menstrual function; sexual function

\begin{abstract}
ABSTRAK
Latar Belakang: Agenesis vagina merupakan salah satu bentuk kelainan yang dijumpai di bidang uroginekologi dengan prevalensi mencapai 1: 4000 kelahiran. Berbagai teknik rekonstruksi baik non pembedahan maupun pembedahan telah diperkenalkan, salah satunya vaginoplasti sigmoid. Penelitian mengenai komplikasi dan luaran dari prosedur vaginoplasti sigmoid masih terbatas.

Tujuan: Untuk menilai komplikasi bedah, luaran fungsi menstruasi dan seksual dari prosedur vaginoplasti sigmoid.

Metode: Penelitian ini menggunakan metode prospektif. Sebanyak 11 pasien dengan variasi kelainan saluran genitalia telah dilakukan prosedur vaginoplasti sigmoid selama Januari 2017 sampai Januari 2019. Data dijabarkan secara deskriptif-analitik. Semua pasien dinilai terhadap adanya komplikasi bedah, luaran fungsi menstruasi dan seksual pasca operasi.

Hasil dan Pembahasan: Sebanyak 10 kasus (90.9\%) didiagnosis dengan agenesis vagina dan 1 kasus (9.1\%) dengan sindrom Mayer-Rokitansky-KüsterHauser (MRKH). Komplikasi durante operasi berupa perdarahan hebat dan cedera rectum terjadi pada 2 kasus (18.2\%). Komplikasi pasca operasi berupa dehisensi luka operasi terjadi pada 2 kasus (18.2\%). Semua pasien yang memiliki uterus (100\%) menunjukkan luaran fungsi menstruasi yang baik. Dari 3 pasien yang telah menikah, semua (100\%) menunjukkan luaran fungsi seksual yang baik pasca operasi (FSFI score 27-30.4).

Kesimpulan: Prosedur vaginoplasti sigmoid merupakan prosedur yang efektif bagi pasien dengan agenesis vagina. Prosedur ini memiliki komplikasi bedah yang rendah dengan luaran fungsi menstruasi dan seksual yang baik.
\end{abstract}

Kata kunci: Vaginoplasti sigmoid; agenesis vagina; fungsi menstruasi; fungsi seksual 


\section{PENDAHULUAN}

Malformasi traktus genital merupakan salah satu bentuk kelainan yang dijumpai di bidang uroginekologi. Sindrom Mayor-Rokitansky KusterHauser (MRKH) dan agenesis vagina merupakan bentuk kelainan kongenital dari absennya vagina. Pada sindrom Mayor-Rokitansky Kuster-Hauser didapatkan juga kelainan uterus selain agenesis pada $2 / 3$ sisi proksimal vagina. Secara prevalensi, sindrom MRKH terjadi pada 1 : 4000-5000 kelahiran ${ }^{1}$, sedangkan insidensi agenesis vagina terisolasi ialah $1: 5000$ kelahiran ${ }^{2}$.

Berbagai macam komplikasi akibat malformasi vagina dapat terjadi. Komplikasi tersebut dapat berupa gangguan menstruasi, infertilitas, dan seksualitas ${ }^{3}$. Target terapi dari malformasi atau absen vagina ialah memperbaiki komplikasi yang timbul, membuat vagina dengan ukuran yang sesuai dan membuat penampilan kosmetik eksternal yang baik ${ }^{4}$.

Teknik rekonstruksi malformasi vagina dapat berupa pembedahan maupun non pembedahan. Beberapa teknik yang sangat popular ialah prosedur Frank, pembedahan Mclndoe, dan teknik Vecchietti ${ }^{5}$. Masing-masing teknik perlu dievaluasi mengenai luaran dan komplikasi yang dihasilkan. Penelitian ini akan membahas mengenai sigmoid vaginoplasty (vaginoplasti sigmoid), suatu teknik rekontruksi yang diperkenalkan oleh Ruge pada tahun 1914, yaitu prosedur menggunakan graft colon sigmoid sebagai neovagina pada rekontruksi malformasi vagina ${ }^{6}$. Pada penelitian ini evaluasi dilakukan terhadap luaran dalam hal fungsi mentruasi, seksual, serta adanya komplikasi pembedahan pada pasien-pasien yang dilakukan vaginoplasti sigmoid di RSUP $d r$. Sardjito Yogyakarta.

\section{METODE}

Pada penelitian ini dilakukan penilaian adanya komplikasi pembedahan, luaran fungsi menstruasi dan seksual pada pasien-pasien malformasi saluran genital yang dilakukan vaginoplasti menggunakan graft colon sigmoid. Desain yang digunakan dalam penelitian ini adalah desain prospective study. Penelitian dilakukan di RSUP dr. Sardjito Yogyakarta (selama 6 bulan, dari bulan Agustus 2018 sampai bulan Januari 2019) untuk mendapatkan jumlah sampel yang memadai. Sampel memenuhi kriteria inklusi berupa pasien yang dilakukan vaginoplasti menggunakan graft colon sigmoid di RSUP dr. Sardjito Yogyakarta, terdiagnosis dengan malformasi saluran genital, serta memiliki rekam medis lengkap. Pengambilan sampel dilakukan dengan cara consecutive sampling method dengan menggunakan data sekunder (rekam medis). Pengambilan sampel berurutan berdasarkan waktu, yaitu berurutan secara retrospektif. Sumber data yang digunakan dalam penelitian ini diambil dari sumber data sekunder yaitu data rekam medis.

Tabel 1. Identifikasi Variabel Penelitian

\begin{tabular}{|c|c|c|c|c|}
\hline \multirow{2}{*}{ Jenis Variabel } & \multirow{2}{*}{ Nama Variabel } & \multirow{2}{*}{ Definisi Operasional } & \multicolumn{2}{|c|}{ Pengukuran } \\
\hline & & & Skala & Penilaian \\
\hline \multirow[t]{2}{*}{ Independent } & $\begin{array}{l}\text { Wanita dengan malformasi } \\
\text { saluran genital }\end{array}$ & $\begin{array}{l}\text { Wanita dengan kelainan kongenital } \\
\text { berupa tidak terbentuknya saluran } \\
\text { reproduksi dengan sempurna }\end{array}$ & Nominal & $\begin{array}{l}\text { 1. Ya } \\
\text { 2. Tidak }\end{array}$ \\
\hline & Vaginoplasti sigmoid & $\begin{array}{l}\text { Pembuatan neovagina dengan } \\
\text { menggunakan graft colon sigmoid }\end{array}$ & Nominal & $\begin{array}{l}\text { 1. Ya } \\
\text { 2. Tidak }\end{array}$ \\
\hline \multirow[t]{3}{*}{ Dependent } & Komplikasi pembedahan & $\begin{array}{l}\text { Komplikasi yang terjadi akibat } \\
\text { tindakan pembedahan vaginoplasti } \\
\text { sigmoid }\end{array}$ & Nominal & \multirow{3}{*}{$\begin{array}{l}\text { 1. Ya } \\
\text { 2. Tidak }\end{array}$} \\
\hline & Luaran fungsi seksual & $\begin{array}{l}\text { Kualitas fungsi seksual dari neovagina } \\
\text { post operasi vaginoplasti sigmoid }\end{array}$ & Ordinal & \\
\hline & Luaran fungsi menstruasi & $\begin{array}{l}\text { Kualitas menstruasi dari neovagina } \\
\text { post operasi vaginoplasti sigmoid }\end{array}$ & Ordinal & \\
\hline
\end{tabular}




\section{HASIL DAN PEMBAHASAN}

Subyek penelitian adalah pasien dengan malformasi saluran ginekologis yang dilakukan tindakan vaginoplasti sigmoid di RSUP Dr. Sardjito Yogyakarta selama januari 2017 sampai januari 2019. Data diambil dari Instalasi Catatan Medis.
Berdasarkan data dari bagian rekam medis, terdapat 11 pasien yang telah menjalani operasi vaginoplasti sigmoid di RSUP Dr. Sardjito Yogyakarta selama periode bulan Januari 2017 sampai dengan Januari 2019. Semua pasien memiliki data rekam medis yang lengkap dan tidak ada yang dieksklusi.

Tabel 2. Karakteristik Subyek Penelitian

\begin{tabular}{clllll}
$\begin{array}{c}\text { Nomor } \\
\text { Subyek }\end{array}$ & \multicolumn{1}{c}{ Inisial } & Usia & Alamat & Status Menikah & Pekerjaan \\
1 & Nn. I & 21 tahun & DIY & Belum menikah & Swasta \\
2 & Nn. SC & 21 tahun & DIY & Belum menikah & Swasta \\
3 & Ny. IR & 25 tahun & Papua & Menikah & IRT \\
4 & Ny. T & 27 tahun & DIY & Menikah & IRT \\
5 & Nn. Y & 14 tahun & Jateng & Belum menikah & Pelajar \\
6 & Ny. MN & 26 tahun & Jateng & Menikah & IRT \\
7 & Nn. B & 12 tahun & Jateng & Belum menikah & Pelajar \\
8 & Nn. S & 14 tahun & Jateng & Belum menikah & Pelajar \\
9 & Nn. D & 14 tahun & Jateng & Belum menikah & Pelajar \\
10 & Ny. SM & 48 tahun & Jateng & Pernah menikah & Swasta \\
11 & Nn. DF & 18 tahun & Jateng & Belum menikah & Pelajar \\
\hline
\end{tabular}

Dari data dapat dilihat bahwa usia pasien dengan kelainan malformasi vaginal yang dilakukan operasi vaginoplasti sigmoid adalah mulai usia 12 tahun sampai dengan 48 tahun. Alamat subyek
$27.3 \%$ berasal dari DIY, sedangkan $72.7 \%$ berasal dari luar DIY. Sebanyak 27.3 \% subyek sedang dalam pernikahan saat ini, $63.6 \%$ belum menikah, sedangkan $9.1 \%$ subyek berstatus pernah menikah.

Tabel 3. Karakteristik Klinis Subyek

\begin{tabular}{|c|c|c|c|c|}
\hline $\begin{array}{l}\text { Nomor } \\
\text { Subyek }\end{array}$ & Paritas & Keluhan & Diagnosis & Riwayat Operasi \\
\hline 1 & POAO & Amenorrhea primer, abdominal pain & $\begin{array}{l}\text { Cervicovaginal } \\
\text { agenesis }\end{array}$ & Ada, $2 \mathrm{X}$ insisi drainase hematometra \\
\hline 2 & POAO & Amenorrhea primer, abdominal pain & Agenesis vagina & $\begin{array}{l}\text { Ada, } 5 \mathrm{X} \text { operasi. vaginaplasty Mc Indoe } \\
\text { (amnion graft), } 4 \mathrm{X} \text { drainase hematometra. }\end{array}$ \\
\hline 3 & POAO & Amenorrhea primer, abdominal pain & Agenesis vagina & Laparotomi $2 \mathrm{X}$ a/I kista endometriosis \\
\hline 4 & POAO & Amenorrhea primer, abdominal pain & Agenesis vagina & $\begin{array}{l}\text { Ada. } 4 \text { X operasi. Drainase hematometra } 3 \mathrm{X} \text {, } \\
\text { Laparotomi appendiktomi }\end{array}$ \\
\hline 5 & POAO & Amenorrhea primer, abdominal pain & Agenesis vagina & Tidak ada \\
\hline 6 & POAO & Amenorrhea primer, abdominal pain & Agenesis vagina & Ada. Operasi drainase vaginoplasti \\
\hline 7 & POAO & Amenorrhea primer, abdominal pain & Agenesis vagina & Ada. Operasi insisi hymen (introitus vagina) \\
\hline 8 & POAO & Amenorrhea primer, abdominal pain & Agenesis vagina & Tidak ada \\
\hline 9 & POAO & Amenorrhea primer, abdominal pain & Agenesis vagina & $\begin{array}{l}\text { Ada. } 2 \text { X operasi. Operasi anoplasti dan insisi } \\
\text { vestibulum vagina }\end{array}$ \\
\hline 10 & POAO & Amenorrhea primer & MRKH & Tidak ada \\
\hline 11 & POAO & Amenorrhea primer, abdominal pain & Agenesis vagina & $\begin{array}{l}\text { Ada. } 2 \mathrm{X} \text { operasi. Vaginoplasti dan laprotomi } \\
\text { drainase hematometra. }\end{array}$ \\
\hline
\end{tabular}


Semua subyek memiliki paritas nullipara (POA0). Sebanyak $90.9 \%$ dengan keluhan utama amenorrhea primer dan abdominal pain, sedangkan $9.1 \%$ dengan amenorreha primer saja. Diagnosis agenesis vagina terdapat pada $90.9 \%$ kasus sementara $9.1 \%$ dengan diagnosis MRKH. Sebanyak 27.3 \% kasus belum pernah menjalani operasi, sedangkan sebagian besar kasus yaitu sebanyak $72.7 \%$ memiliki berbagai macam riwayat operasi.

Tabel 4. Karakteristik Komplikasi Pembedahan

\begin{tabular}{|c|c|c|c|}
\hline $\begin{array}{l}\text { Nomor } \\
\text { Subyek }\end{array}$ & Prosedur Operasi & $\begin{array}{l}\text { Komplikasi Durante } \\
\text { Operasi }\end{array}$ & Komplikasi Pasca Operasi \\
\hline 1 & $\begin{array}{l}\text { Laparotomi vaginoplasti sigmoid, parsial } \\
\text { salpingoooforektomi sinistra }\end{array}$ & Tidak ada & Tidak ada \\
\hline 2 & Laparotomi vaginolasti sigmoid, appendiktomi & Tidak ada & Tidak ada \\
\hline 3 & $\begin{array}{l}\text { Relaparotomi parsial kistektomi sinistra, } \\
\text { meatotomi sinistra, rekonstruksi tuba sinistra, } \\
\text { vaginoplasti sigmoid, adhesiolisis, fulgurasi }\end{array}$ & $\begin{array}{l}\text { Perdarahan } \\
(1300 \mathrm{~mL})\end{array}$ & Dehisensi luka operasi (Rawat jalan) \\
\hline 4 & Laparotomi vaginoplasti sigmoid & Tidak ada & Tidak ada \\
\hline 5 & Laparotomi vaginoplasti sigmoid & Tidak ada & Tidak ada \\
\hline 6 & $\begin{array}{l}\text { Laparotomi adhesiolisis, kistektomi dekstra, } \\
\text { vaginoplasti sigmoid, repair fistula rektovagina, } \\
\text { iliostomi protektif }\end{array}$ & Tidak ada & Tidak ada \\
\hline 7 & $\begin{array}{l}\text { Sistoskopi, insersi UK kiri, eksplorasi buli, } \\
\text { laparotomi adhesiolisis, vaginoplasti sigmoid, } \\
\text { kistektomi bilateral, meatotomi bilateral }\end{array}$ & Tidak ada & Tidak ada \\
\hline 8 & Laparotomi vaginoplasti sigmoid & Tidak ada & Tidak ada \\
\hline 9 & Laparotomi vaginoplasti sigmoid & Tidak ada & Tidak ada \\
\hline 10 & Vaginoplasti sigmoid & Tidak ada & Tidak ada \\
\hline 11 & Relaparotomi vaginoplasti sigmoid, fulgurasi & $\begin{array}{c}\text { Cedera rectum } \\
\text { (perdarahan } 1000 \mathrm{~mL} \text { ) }\end{array}$ & $\begin{array}{l}\text { Dehisensi luka operasi (dehisensi total), } \\
\text { dilakukan reclosing } 10 \text { hari pasca operasi }\end{array}$ \\
\hline
\end{tabular}

Dari data dapat dilihat bahwa komplikasi durante operasi terjadi pada sebanyak $18.2 \%$ kasus (perdarahan dan cedera rectum). Komplikasi pasca operasi juga terjadi sebanyak $18.2 \%$ pada pasien yang sama (dehisensi luka operasi).

Tabel 5. Karakteristik Luaran Fungsi Menstruasi

\begin{tabular}{ccc}
$\begin{array}{c}\text { Nomor } \\
\text { Subyek }\end{array}$ & Pola Menstruasi Pasca Operasi & $\begin{array}{c}\text { Menstruasi Pertama } \\
\text { Pasca Operasi(Interval) }\end{array}$ \\
1 & Menstruasi teratur: siklus 5-8 hari, 2-3 kali ganti pembalut/hari, dismenorrhea (-) & 30 hari pasca operasi \\
2 & Menstruasi teratur: siklus 7 hari, $2-3$ kali ganti pembalut/hari, dismenorrhea (-) & 30 hari pasca operasi \\
3 & Menstruasi teratur: siklus 6-7 hari, 2-3 kali ganti pembalut/hari, dismenorrhea (-) & 8 hari pasca operasi \\
4 & Menstruasi teratur: siklus 3-4 hari, 2-3 kali ganti pembalut/hari, dismenorrhea (-) & 25 hari pasca operasi \\
5 & Menstruasi teratur: siklus 7 hari, 2-3 kali ganti pembalut/hari, dismenorrhea (-) & 28 hari pasca operasi \\
6 & Menstruasi teratur: siklus 5 hari, 2-3 kali ganti pembalut/hari, dismenorrhea (-) & 30 hari pasca operasi \\
7 & Menstruasi teratur: siklus 7 hari, 2-3 kali ganti pembalut/hari, dismenorrhea (-) & 30 hari pasca operasi \\
8 & Menstruasi teratur: siklus 7 hari, 2-3 kali ganti pembalut/hari, dismenorrhea (-) & 15 hari pasca operasi \\
9 & Menstruasi teratur: siklus 7 hari, 2-3 kali ganti pembalut/hari, dismenorrhea (-) & 17 hari pasca operasi \\
10 & Menstruasi teratur: siklus 5-7 hari, 2-3 kali ganti pembalut/hari, dismenorrhea (-) & 30 hari pasca operasi \\
11 & Menstruasi teratur: siklus 5-7 hari, 2-3 kali ganti pembalut/hari, dismenorrhea (-) & 28 hari pasca operasi \\
\hline
\end{tabular}


Tabel 6. Karakteristik Keluaran Fungsi Seksual

\begin{tabular}{ccc} 
Nomor & Status Menikah & FSFI Score \\
Subyek & Menikah & 27 \\
3 & Menikah & 29.4 \\
4 & Menikah & 30.4 \\
\hline
\end{tabular}

Seluruh kasus (100\%) pasca operasi vaginoplasti sigmoid memiliki luaran fungsi menstruasi maupun seksual yang baik. Interval antara operasi dan mulai menstruasi pertama pasca operasi bervariasi, mulai 8 hari sampai dengan 30 hari pasca operasi. Untuk luaran fungsi seksual yang dinilai dengan FSFI score pada pasien yang telah menikah, nilai FSFI score berada di rentang 27 sampai dengan 30.4 .

\section{PEMBAHASAN}

Prosedur vaginoplasti sigmoid merupakan salah satu teknik pembedahan dalam manajemen malformasi saluran genital. Prosedur ini aman dan memiliki angka morbiditas yang rendah7. Pada penelitian ini dijumpai adanya dua subyek yang mengalami komplikasi durante dan pasca operasi. Komplikasi durante operasi yang dialami ialah perdarahan $(1000 \mathrm{~mL})$ pada subyek 3 dan perdarahan $(1300 \mathrm{~mL})$ disertai cedera rectum pada subyek 11. Komplikasi pasca operasi berupa dehisensi luka pasca operasi terjadi pada subyek yang sama. Subyek 11 mengalami dehisensi total sehingga memerlukan operasi reclosing. Faktor risiko terjadinya perdarahan dan cedera rectum pada kedua pasien di atas ialah adanya riwayat operasi baik abdominal dan vaginal. Seperti diketahui dari penelitian sebelumnya bahwa riwayat operasi akan menjadi faktor risiko terjadinya adhesi yang akan meningkatkan risiko perdarahan dan cedera organ dalam durante operasi selanjutnya. Untuk komplikasi pasca operasi, yaitu dehisensi luka operasi, yang menjadi faktor risiko pada subyek 3 dan 11 ialah jumlah perdarahan durante operasi, irisan linea mediana, dan durasi operasi yang panjang ${ }^{8-10}$. Penggunaan drain subkutan dapat menurunkan risiko dehisensi luka operasi pada pasien yang berisiko tinggi terjadinya dehisensi luka operasi $^{11,12}$.

Dari penelitian sebelumnya, didapatkan bahwa vaginoplasti sigmoid memberikan hasil estetika, fungsi seksual yang baik dan angka kejadian stenosis yang rendah ${ }^{13,14}$. Namun perlu diperhatikan bahwa perawatan dengan dilatasi mekanis pasca bedah perlu dilakukan hingga 6-12 bulan pasca operasi untuk mencegah stenosis ${ }^{15}$. Pada penelitian ini, semua subyek memberikan luaran fungsi menstruasi maupun seksual yang baik.

\section{KESIMPULAN DAN SARAN}

Prosedur vaginoplasti sigmoid merupakan prosedur yang efektif bagi pasien dengan agenesis vagina. Prosedur ini memiliki komplikasi bedah yang rendah dengan luaran fungsi menstruasi dan seksual yang baik.

Perlu evaluasi lebih lanjut terkait analisis persiapan operasi, pemeriksaan penunjang yang dilakukan, penggunaan antibiotika, termasuk pemberian nutrisi sebelum maupun setelah operasi, maupun teknik operasi itu sendiri.

\section{DAFTAR PUSTAKA}

1. Kapoor R, Sharma DK, Singh KJ, Suri A, Singh $P$, Chaudhary $\mathrm{H}$, et al. Sigmoid vaginoplasty: Long-term results. Urology. 2006; 67(6): 1212-5

2. Kim SK, Park JW, Lim KR, Lee KC. Is rectosigmoid vaginoplasty still useful?. Arch Plast Surg. 2017; 44(1): 48-52

3. Morcel K, Camborieux L, Guerrier D. MayerRokitansky-Kuster-Hauser (MRKH) syndrome. Orphanet J Rare Dis. 2007; 2: 13

4. Powell DM, Newman KD, Randolph J. A proposed classification of vaginal anomalies and their surgical correction. J Pediatr Surg. 1995; 30: 271-5; discussion 275-6

5. Carrard C, Chevret-Measson M, Lunel A, Raudrant D. Sexuality after sigmoid vaginoplasty in patients with Mayer-Rokitansky-Küster-Hauser syndrome. Fertil Steril. 2012; 97(3): 691-6

6. Salgado CJ, Nugent A, Kuhn J, Janette M, Bahna H. Primary Sigmoid Vaginoplasty in Transwomen: Technique and Outcomes. Biomed Res Int. 2018 
7. Bouman MB, Buncamper ME, B van der Sluis W, and Meijerink WJHJ. Total Laparoscopic Sigmoid Vaginoplasty. In: Total laparoscopic sigmoid vaginoplasty: A novel technique for primary and revision vaginoplasty. PhD-Thesis of Mark-Bram Bouman, Plastic Reconstructive and Gendersurgeon Department of Plastic Reconstructive and Hand Surgery, VUmc, Amsterdam. 2016.

8. Barmparas G, Branco BC, Schnüriger B, Lam L, Inaba $\mathrm{K}$, Demetriades D. The Incidence and Risk Factors of Post-Laparotomy Adhesive Small Bowel Obstruction. J Gastrointest Surg. 2010; 14(10): 1619-28

9. Makela J, Kiviniemi H, Juvonen T. Factors influencing wound dehiscence after midline laparotomy. Am J of surgery. 1995; 170 (4): 387-90

10. Sivender A, Ilaiah M, Reddy GS. Clinical study on risk factors causing abdominal wound dehiscence and management. J of Dental and Med Sci. 2015; 14(10): 18-23
11. Sumi Y, Yamashita K, Kanemitsu K, Kanaji S. Effects of Subcutaneous Closed Suction Drain for the Prevention of Incisional SSI in Patients with Colorectal Perforation. Surgical Science. 2014; 05(03): 122-7

12. Hirose $Y$, Naiki T, Ando R, Nakane A, Etani T, lida K, et.al. Clinical Study: Novel Closing Method Using Subcutaneous Continuous Drain for Preventing Surgical Site Infections in Radical Cystectomy. Hindawi Publishing Corporation Urology. 2014.

13. Nowier A, Esmat M, Hamza RT. Surgical and functional outcomes of sigmoid vaginoplasty among patients with variants of disorders of sex development. Int Braz J Urol. 2012; 38(3): 380-8

14. Hanna MK. Vaginal construction. Urology. 1987; 29(3): 272-5

15. Cao L, Wang Y, Li Y, Xu H. Prospective randomized comparison of laparoscopic peritoneal vaginoplasty with laparoscopic sigmoid vaginoplasty for treating congenital vaginal agenesis. International Urogynecology Journal. 2013; 24(7): 1173-9 